INTERNATIONAL

FOOD POLICY

RESEARCH

INSTITUTE

IFPRI

IFPRI Discussion Paper 01375

September 2014

\title{
Costing Alternative Transfer Modalities
}

\section{Amy Margolies}

John Hoddinott

Poverty, Health, and Nutrition Division 


\section{INTERNATIONAL FOOD POLICY RESEARCH INSTITUTE}

The International Food Policy Research Institute (IFPRI), established in 1975, provides evidence-based policy solutions to sustainably end hunger and malnutrition and reduce poverty. The institute conducts research, communicates results, optimizes partnerships, and builds capacity to ensure sustainable food production, promote healthy food systems, improve markets and trade, transform agriculture, build resilience, and strengthen institutions and governance. Gender is considered in all of the institute's work. IFPRI collaborates with partners around the world, including development implementers, public institutions, the private sector, and farmers' organizations, to ensure that local, national, regional, and global food policies are based on evidence. IFPRI is a member of the CGIAR Consortium.

\section{AUTHORS}

Amy Margolies (amargo10@jhu.edu) was a senior research analyst in the Poverty, Health, and Nutrition Division of the International Food Policy Research Institute (IFPRI), Washington, DC, when she wrote this work. She is currently a doctoral student at the Bloomberg School of Public Health at Johns Hopkins University, Baltimore, MD.

John Hoddinott (J.Hoddinott@cgiar.org) is a senior research fellow in the Poverty, Health, and Nutrition Division of IFPRI, Washington, DC.

\section{Notices}

IFPRI Discussion Papers contain preliminary material and research results and are circulated in order to stimulate discussion and critical comment. They have not been subject to a formal external review via IFPRI's Publications Review Committee. Any opinions stated herein are those of the author(s) and are not necessarily representative of or endorsed by the International Food Policy Research Institute.

Copyright 2014 International Food Policy Research Institute. All rights reserved. Sections of this material may be reproduced for personal and not-for-profit use without the express written permission of but with acknowledgment to IFPRI. To reproduce the material contained herein for profit or commercial use requires express written permission. To obtain permission, contact the Communications Division at ifpri-copyright@cgiar.org. 


\section{Contents}

Abstract $\quad$ V

Acknowledgments $\quad$ vi

1. Introduction 1

2. The Four-Country Study 2

3. Methods 3

4. Results

5. Accounting for Food Procurement Costs 11

6. The Impact of Modality-Specific Cost Differences on Coverage 13

7. Conclusion 15

$\begin{array}{ll}\text { References } & 16\end{array}$ 


\section{Tables}

3.1 Activity-based costing for Ecuador cash-food-voucher study 4

4.1 Modality-specific transfer costs in Ecuador, Uganda, Yemen, and Niger 8

$\begin{array}{ll}4.2 \text { Private costs of obtaining transfers } & 10\end{array}$

5.1 Accounting for procurement costs in Ecuador and Yemen 12

6.1 Impact of modality-specific cost differences on coverage 14 


\begin{abstract}
Discussions regarding the merits of cash and food transfers by academics and implementers alike focus on their relative impacts. Much less is known about their relative costs. We apply activity-based costing methods to interventions situated in Ecuador, Niger, Uganda, and Yemen, finding that the per transfer cost of providing cash is always less than that of providing food. Given the budget for these interventions, an additional 44,769 people could have received assistance at no additional cost had cash been provided instead of food. This suggests a significant opportunity cost in terms of reduced coverage when highercost transfer modalities are used. Decisions to use cash or food transfers should consider both impacts and costs.
\end{abstract}

Keywords: costing; social protection; food aid; cash transfers; multicountry 


\section{ACKNOWLEDGMENTS}

We thank World Food Programme (WFP) colleagues in Ecuador, Niger, Uganda, and Yemen for their assistance in the collation of the costing data and David Ryckembusch for valuable assistance in providing access to and interpretation of WFP procurement data. This work was undertaken as part of the CGIAR Research Program on Policies, Institutions, and Markets led by the International Food Policy

Research Institute (IFPRI). Funding support for this study was provided by WFP through a grant from the government of Spain and the CGIAR Research Program on Policies, Institutions, and Markets. The opinions expressed here belong to the authors. 


\section{INTRODUCTION}

Many developing countries are increasing the size and scope of their social protection programs. Undertaking this expansion successfully requires addressing a series of technical questions, including regarding the intended target group, targeting mechanisms used to reach those beneficiaries, the size and frequency of transfers, and the transfer type - cash, food or other in-kind resource, or some form of nearcash transfer such as a voucher. This last issue, the type of transfer, has long produced a polarized and acrimonious debate (Devereux 2006). More recently, efforts have been made to assess in a more rigorous fashion the relative benefits of cash, food, and near-cash transfers; see Hidrobo et al. (2014) for a summary. However, benefits of any given transfer modality must be assessed against the cost of their delivery. As an example, from the perspective of program designers, if one modality produces only a modest increase in benefits relative to another but is considerably more expensive to implement, it may be more desirable to use the less effective modality but reach a larger population.

Relative to the number of studies that assess the impact of social protection interventions, much less is known about implementation costs. Less than a quarter of the social protection programs listed in Coady, Grosh, and Hoddinott (2004) have costing information, and Grosh et al.'s (2008) magisterial review of social protection interventions also contains relatively few studies with costing data. Caldés, Coady, and Maluccio (2006) provide examples of how to assess the costs of a conditional cash transfer program, and Harou et al. (2013) and Lentz, Passarelli, and Barrett (2013) compare costs of alternative means of procuring food. But while it is frequently asserted that cash is cheaper to deliver than food, evidence of the magnitude of these relative cost differences is hard to come by.

Within this context, this paper makes two contributions. First, we show how an adaptation of a method used in the health economics literature can provide estimates of the full economic costs of alternative transfer modalities. Second, we apply that method to compare the costs of delivering food or cash (and in one case, vouchers) to beneficiaries in pilot interventions situated in four very different contexts: peri-urban Ecuador, semipastoral Niger, rural northern Uganda, and smallholder settlements in Yemen. A feature of these comparisons is that all other aspects of the interventions - the targeting of beneficiaries, the size and duration of transfers, and so on-were designed to be the same for the different transfer modalities in each country. This means that our comparisons of the cost of delivering alternative modalities are not confounded by other differences in program design.

The paper is organized as follows. Section 2 provides contextual information on the four-country study. Section 3 describes the methods for calculating the comparative costs using the Ecuador case study as an example. Section 4 gives results for all four countries. Section 5 extends the analysis by relaxing assumptions we make about the cost of sourcing food. Section 6 further extends the analysis to assess the opportunity costs associated with choosing higher-cost transfer modalities, and section 7 concludes. 


\section{THE FOUR-COUNTRY STUDY}

In partnership with the World Food Programme (WFP), we participated in a four-country study to assess the comparative performance of cash transfers, food payments, and vouchers on household food security. The studies in Ecuador, Uganda, Niger, and Yemen were carried out over the 2010-2012 period. In all countries, an experimental design was used with modalities (cash, food, vouchers) randomly assigned at a locality level. The timing, frequency, and value of transfers were equalized to the extent possible across modalities, thus ensuring that differences in outcomes were attributable to the modality and not to other confounding factors. All studies took place in localities with well-functioning grain markets. The four countries were chosen to cover the range of contexts in which WFP works. In Ecuador, the pilot ${ }^{1}$ was undertaken in an urban area with a refugee population, with easy access to banks and markets selling a wide range of foods. The study in Niger represents a rural, classic Sahelian food security setting with very poor households facing severe seasonal food shortages. The Uganda study was also undertaken in a rural setting in the north, which was additionally a postconflict area. The Yemen intervention took place in a poor and conflict-prone setting where there were concerns that cash would be used to purchase qat, a mild narcotic that is widely consumed.

In Ecuador, unconditional transfers were made in two northern provinces (Carchi and Sucumbíos) with large concentrations of Colombian refugees and poor host Ecuadorians. Beneficiaries were randomized at the barrio (neighborhood) level to receive US $\$ 40$ cash transfers that were accessed from ATMs using a debit card, $\$ 40$ in vouchers redeemable for specified foods in supermarkets, or $\$ 40$ in food-rice (24 kilograms $(\mathrm{kg})$ ), vegetable oil (4 liters $(\ell))$, lentils $(8 \mathrm{~kg})$, and canned sardines (eight cans of $0.425 \mathrm{~kg}){ }^{2}$ Transfers were received monthly for a six-month period. All beneficiaries also received nutrition sensitization training.

In Niger, transfers were provided conditional on public works for three months (all households) and unconditionally for three months (targeted households) in the Zinder region, where there are high levels of chronic and transitory food insecurity. Beneficiaries were randomized at the worksite level to receive a cash payment of 25,000 FCFA (\$55) per month or an in-kind payment of $87.5 \mathrm{~kg}$ of cereals, 18 $\mathrm{kg}$ of pulses, and $3.5 \mathrm{~kg}$ of vegetable oil and salt. Payments were made every two weeks during public works and monthly for unconditional transfers. Cash payments were made via a mobile ATM that was transported to villages; each beneficiary received a debit card that was used to withdraw funds.

In northern Uganda, transfers were linked to children's enrollment in early childhood development centers (preschools) in three districts of Karamoja — a poor, rugged, postconflict subregion with high seasonal food insecurity. For each child aged 3-5 years enrolled in preschool, beneficiaries were randomized at the preschool level to receive 25,500 UGX $(\$ 10.25)$ in cash, added electronically to mobile money cards, or 25,500 UGX worth of food-multiple-micronutrient-fortified corn-soya blend, vitamin A-fortified oil, and sugar. Transfers were distributed every six to eight weeks for 12 months (six transfer cycles). Transfers were made preferentially to the child's mother.

In Yemen, unconditional transfers were distributed in rural districts of two governorates (Hajjah and Ibb) with high baseline levels of food insecurity. Randomization was done at the food distribution point level. Each distribution point is a school serving a cluster of neighboring villages. Cash and food groups received three transfers each: a cash transfer of 10,500 YER (\$49) every two months beginning in November 2011; or a food basket consisting of $50 \mathrm{~kg}$ of fortified wheat flour and $5 \ell$ of oil in August 2011, October 2011, and April 2012.

\footnotetext{
${ }^{1}$ All four country studies were pilot interventions. Pilot programs may require greater start-up costs in contrast to established programs, and variable costs may decline over time as staff become accustomed to implementation processes. Conversely, scaling up will not result in declining costs if there is less scope for learning by doing or scale economies do not exist.

${ }^{2}$ All dollars are US dollars.
} 


\section{METHODS}

In a typical program budget, expenditures are grouped by category or line item. For a social protection intervention, they include the cost of transfers to beneficiaries, staff time, transport, materials, bank charges (for cash transfers), storage (for in-kind transfers such as food) and overhead costs such as office space, and management costs. Although accounts based on these categories tell us how much it costs to administer an intervention, they are less helpful when we want to compare the relative costs of alternative transfer modalities. For example, staff costs are expressed in terms of salaries and benefits paid for all aspects of an intervention: design, selection of beneficiaries, oversight of implementation, reporting, and audit. Information from accounts expressed in this way cannot tell us if it would be cheaper to shift from one transfer modality to another. Instead, we need a means of allocating differences in project costs to each of the activities involved in implementing a transfer program.

One such approach is the activity-based costing-ingredients method (ABC-I). This approach combines activity-based accounting methods with the "ingredients" method, which calculates program costs from inputs, input quantities, and input unit costs (Kaplan and Anderson 2004; Fiedler, Villalobos, and de Mattos 2008; Tan-Torres Edejer et al. 2003). 3 Note that our interest is in costing out the activities specifically associated with delivering cash transfers, food transfers, and vouchers. We are not interested in the costs that are common across all transfer modalities, such as those associated with beneficiary selection; rather we are concerned with costs specific to a given transfer modality.

Understanding the ingredients, activities, and associated costs of a modality requires detailed understanding of how such modalities are implemented. As outlined in Kaplan and Anderson (2004), we rely on three methods: focus group discussions with program staff, key informant interviews with implementers and managers, and a limited amount of direct observation.4 Our initial focus group discussions played an especially important role to develop the initial list of activities for each modality. We refined the lists through further communication with key informants and direct observation. We then developed an understanding of how much time it took to complete these activities. We implemented a staff time allocation questionnaire that was distributed to all WFP employees participating in any component of program operations. The questionnaire provided the crucial information on the cost of staff time spent on different program-related activities. WFP also shared data from its internal accounting system, WINGS, which provided us with information on the cost of material inputs (for example, the cost of printing vouchers).

\section{Ecuador Case Study}

Table 3.1 provides a detailed breakdown of the modality-specific costs for the Ecuador case study, disaggregating by WFP staff costs and materials, services, transport, and other non-WFP staff costs. The first set of rows describes the costs associated with the cash transfers. Cash payments to beneficiaries were made monthly by transferring $\$ 40$ onto a pre-programmed debit card that could be used in an ATM. Implementing this process required identifying and contracting with a bank willing to provide the service, and paying the costs associated with the production of the debit cards, wire fees associated with transferring funds from WFP to the bank, and staff costs associated with monitoring this payment process. For example, staff monitoring costs could include troubleshooting when beneficiaries had difficulties using their debit cards and spot checks to make sure that beneficiaries were not being denied access to ATMs.

\footnotetext{
${ }^{3}$ Use of $\mathrm{ABC}$ methods in manufacturing and health care has become increasingly common over the last 30 years. A detailed bibliography and history of their application is beyond the scope of this paper; Turney (1996) provides an introduction, brief early history, and bibliography. We note that other attractive features of the ABC-I method include the ability to account for opportunity costs, quantified as economic costs, in the total program costs. It also allows for the incorporation of "off-budget" expenditures - for example, donated goods or services that otherwise would not be included as program operating costs.

${ }^{4}$ Kaplan and Anderson (2004) note that time logs are another means of obtaining information, but the WFP staff responsible for implementing these interventions did not keep time logs.
} 


\begin{tabular}{|c|c|c|c|c|c|c|}
\hline & \multicolumn{6}{|c|}{ Transfer modality } \\
\hline & \multicolumn{2}{|r|}{ Cash } & \multicolumn{2}{|c|}{ Voucher } & \multicolumn{2}{|c|}{ Food } \\
\hline & $\begin{array}{l}\text { Cost of } \\
\text { WFP } \\
\text { staff } \\
\text { time }\end{array}$ & $\begin{array}{c}\text { Materials, } \\
\text { services, } \\
\text { transport, and } \\
\text { other non-WFP } \\
\text { staff costs }\end{array}$ & $\begin{array}{l}\text { Cost of } \\
\text { WFP } \\
\text { staff } \\
\text { time }\end{array}$ & $\begin{array}{c}\text { Materials, } \\
\text { services, } \\
\text { transport, and } \\
\text { other non-WFP } \\
\text { staff costs }\end{array}$ & $\begin{array}{c}\text { Cost of } \\
\text { WFP and } \\
\text { NGO staff } \\
\text { time }\end{array}$ & $\begin{array}{l}\text { Materials, } \\
\text { services, } \\
\text { transport, and } \\
\text { other non-WFP } \\
\text { staff costs }\end{array}$ \\
\hline Activity & \multicolumn{6}{|c|}{ All costs in US \$ } \\
\hline Developing contracts with banks for cash transfers & 1,183 & - & - & - & - & - \\
\hline Production of debit cards & - & 13,219 & - & - & - & - \\
\hline Wire fees & - & 215 & - & - & - & - \\
\hline Monitoring cash payments & 3,799 & 773 & - & - & - & - \\
\hline Scoping activities for supermarket selection & - & - & 1,374 & - & - & - \\
\hline Negotiation of contracts with supermarkets & - & - & 2,398 & 884 & - & - \\
\hline Voucher design and printing & - & - & 11,275 & 582 & - & - \\
\hline Voucher liquidation & - & - & 6,857 & - & - & - \\
\hline Identification of food storage facilities & - & - & - & - & 2,341 & - \\
\hline Food storage rental costs & - & - & - & - & - & 22,519 \\
\hline Food storage, repair costs & - & - & - & - & - & 2,096 \\
\hline Ration preparation & - & - & - & - & - & 18,764 \\
\hline Food distribution (WFP) & - & - & - & - & 4,365 & - \\
\hline Food distribution (NGO) & - & - & - & - & 10,244 & 1,500 \\
\hline Travel preparation & 74 & - & 85 & 1,118 & 53 & - \\
\hline Payment execution & 2,794 & - & 2,604 & - & 282 & - \\
\hline Project monitoring & 1,014 & - & 1,078 & - & 884 & - \\
\hline Column total & 8,863 & 14,207 & 25,672 & 2,584 & 18,169 & 44,879 \\
\hline Total modality-specific cost & \multicolumn{2}{|r|}{23,070} & \multicolumn{2}{|r|}{28,256} & \multicolumn{2}{|c|}{63,048} \\
\hline Share of total cost & $38 \%$ & $62 \%$ & $91 \%$ & $9 \%$ & $29 \%$ & $71 \%$ \\
\hline Cost per transfer & \multicolumn{2}{|r|}{$\$ 2.99$} & \multicolumn{2}{|r|}{$\$ 3.27$} & \multicolumn{2}{|c|}{$\$ 11.46$} \\
\hline
\end{tabular}

Source: Authors' calculations. 
Similarly, a variety of activities were necessary for the implementation of the voucher modality. The first activity was the assessment, selection, and establishment of contractual agreements with supermarkets. Staff time was then needed to design a voucher that was readily identifiable as a voucher and was resistant to tampering or duplication. Material resources in the form of paper and printing costs were necessary to produce the vouchers for distribution to beneficiaries. WFP staff conducted voucher distribution ensuring that beneficiary IDs were matched with voucher serial numbers. Supermarkets collected used vouchers on a monthly basis and submitted them to WFP sub-offices in addition to a liquidation report that included collated and printed receipts of purchases with signature. The WFP suboffice counted and verified liquidation reports and reconciled them with the supermarket vouchers, checking ID numbers in their beneficiary database. Liquidated vouchers were sent to the WFP country headquarters, where they were reviewed and confirmed. The country office then sent an order of payment through the WINGS finance system and notified the bank to initiate payment. The partner bank then executed payments to the participating supermarkets for the amounts specified in the redeemed vouchers. As a final step, WFP updated its database to reflect the full liquidation of vouchers issued.

The modality-specific costs for the food transfer center on those costs unique to moving commodities - namely, storage, packing, and distribution. Activity costs for food encompassed work conducted in the warehouse for the monitoring of logistics for shipments, product inventory, and supervision of ration preparation and packaging. WFP contracted two locally based international nongovernmental organizations (NGOs) to conduct distribution activities in the subregions of Carchi and Sucumbíos. As each WFP program requires a different selection of commodity type and quantity, preparation and repackaging of rations is necessary to appropriately fit the desired composition of the food basket. There are also human resource costs for WFP to manage the storage of these commodities in its warehouses until they are transferred to the implementing partner NGOs for regional distribution. Other food-handling-related costs included monthly rental costs for NGO warehouses as well as those material costs for repairs and investment in facilities. WFP staff costs were incurred for transport of commodities to warehouses, and the NGO partners had both staffing and material costs for cars, gas, and maintenance for the food distribution activities that included moving commodities and delivery to program beneficiaries.

Note that these calculations largely exclude activities common to all modalities. Those include items such as overhead costs for offices, data monitoring, or the selection of beneficiaries for program participants. However, some common costs differ slightly depending on the modality. For example, in Uganda the cost of producing ID cards was higher for cash than food as the cash card had a photo instead of the simple printed food ration card. In Yemen, both food and cash required mobilization and sensitization costs to make participants aware of the program activities; however, as cash was a newer modality type more staff time was invested. In Ecuador, administrative and logistics procedures for program operations, such as preparation for staff travel, the execution of payments (through the finance department), and monitoring of program activities (collecting data to verify delivery of transfer, and so on) differed slightly by modality.

The last four rows of Table 3.1 summarize the Ecuador data by transfer modality. There are several findings of note. Suppose we observed only the non-WFP staff costs such as materials, services, and transport. Table 3.1 indicates that vouchers were the least costly transfer modality for this category, requiring an expenditure of only $\$ 2,584$. Relative to vouchers, cash transfers would seem to be much more expensive, requiring $\$ 14,207$ to administer. The non-WFP staff costs of food transfers are three times that of cash, $\$ 44,879$. However, once we account for WFP staff costs, the relative positions of cash and vouchers change. Vouchers required substantially more staff time to administer, \$25,672, compared with $\$ 8,863$ for cash. Food transfers required $\$ 18,169$. The total modality-specific costs were $\$ 23,071$ for cash, $\$ 28,256$ for vouchers, and $\$ 63,048$ for food. 
Two additional comments are worth making. First, based on these data, we can calculate a cost transfer value (Caldes, Coady, and Maluccio 2006). Modality-specific costs are the sum of all material and staff-based costs unique to that modality. Subsequently, the modality-specific cost transfer value is the total cost divided by the total number of transfers distributed for that modality. To provide an example, in the case of cash in Ecuador, the total modality-specific cost of cash was $\$ 23,070$. The total number of transfers delivered across six rounds of distribution was 7,705. The cost per transfer is thus $\$ 2.99$.

Second, there is a distinction between fixed and variable costs. Would we get the same pattern if the intervention were to last a year or longer rather than six months? In the case of Ecuador, both cash and vouchers have fixed costs of setting up contracts and operations with the banks and supermarkets, respectively. The variable costs of these modalities, however, will incur minimal increases along with extended program duration, as the variable costs of printing extra vouchers or producing extra debit cards and associated fees are low. One might also expect to see a smoothing of staff time invested in these modalities as well because the effort involved in setting up new program pilots can be expected to be more labor intensive than a previously established modality such as the food transfer. In the case of food, the rental of the storage facility can be assumed to be a fixed cost, assuming that the volume of food transferred does not increase to the extent that additional storage space is required. However, food incurs fixed significant costs - for instance, the cost of transport for distribution, packaging, and preparation of rations. For example, the per unit cost of packaging a ration remains constant even if the volume of rations transferred increases. Therefore, we would not foresee the cost of the food transfer to decrease over time. Conversely, the costs of cash and vouchers could decrease due to low variable costs and to economies of scale. To see the effect of this, suppose we extend each program by six months so that additional transfers are made. A rough calculation, on the strong assumption that no other costs change, suggests that this would decrease modality-specific costs per transfer across all program modalities. However, the potential decrease in cost per transfer is greater in the cash modality (-62 percent, from $\$ 2.99$ to $\$ 1.13)$ than in the case of vouchers (-17 percent, from $\$ 3.27$ to $\$ 2.73$ ) or food (-4 percent, from $\$ 11.46$ to $\$ 11.03)$. 


\section{RESULTS}

We apply the ABC-I method to three country studies of WFP programs in Ecuador, Uganda, and Yemen. Results are found in Table 4.1. Cost centers (categories) were standardized to facilitate groupings of related activities across country contexts. For example, in one country fumigation costs for warehousing food rations may have been a cost ingredient for the food modality but was not necessary in another country. The activity cost of "food storage and packaging" aggregates those cost ingredients that may not be the same across country contexts but that are nonetheless appropriate inputs into that cost category.

The activity cost center groupings allowed for analysis across country contexts, despite some variation in actual inputs and sub-activities. The principal activities for each modality and country are listed in the lower panel of Table 4.1 .

Calculation of modality-specific costs for the fourth country in Table 4.1, Niger, did not require the ABC-I method. Program implementation was subcontracted to several Nigerian NGOs that were responsible for overseeing public works operations, selecting beneficiaries for the unconditional transfers, and making both food and cash payments. In villages selected for cash transfers, those NGOs charged WFP a 6 percent fee based on the value of cash transfers that were made. In villages selected for food transfers, payments to the NGOs were based on the cost per metric ton of transporting and distributing food to beneficiaries. In addition to those costs, WFP was responsible for purchasing the debit cards used by beneficiaries and for transporting food to the NGOs operating in Zinder. ${ }^{5}$ Given these contractual arrangements, we are not able to separate out the cost of WFP staff time from materials, services, transport, and other non-WFP staff costs.

Across all countries, the per transfer cost of providing cash is always less than food. The per transfer cost of cash ranges within a narrow band, between \$2.89 in Niger and \$3.24 in Uganda. The cost per food transfer varies more widely across countries, reflecting the different settings in which such transfers take place. The cost of making a food transfer ranges from $\$ 6.41$ (Uganda) to $\$ 11.46$ (Ecuador). On a per transfer basis, cash costs $\$ 3.17$ less to deliver to a beneficiary in Uganda, $\$ 6.80$ less in Yemen, $\$ 7.38$ less in Niger, and $\$ 8.47$ less in Ecuador.

A principal cost driver across all countries for the food transfer modality is distribution and transport of commodities. The distribution cost category is inclusive of land transport in-country, including movement from central storage facilities to regional facilities and the transport cost of delivery to distribution points as well as any associated insurance or human resource costs necessary to complete those activities. Thus, the cost of distribution varies in accordance with geographic context and dispersion of delivery sites. Transport costs can also be affected by the price of fuel, drivers' wages, and other transport-related inputs. Note that given the volume of these transfers and the fact that they must all be transported by road, there is little possibility of exploiting economies of scale in distribution. Examining human resource costs for the food modality across the three countries, the most labor-intensive activities were for distribution and monitoring in Uganda and Ecuador, and for the logistics of implementation in Yemen. The difference in distribution costs between Ecuador, Uganda, and Yemen can be explained partially by geographic differences (peri-urban in Ecuador and rural in Uganda and Yemen). In Ecuador, storage costs were greater than the distribution costs, as they covered both the costs of WFP storage as well as partner NGOs in the subregions. However, as distribution sites were located close to beneficiary households, participants traveled to local storage sites to collect their transfers. By contrast, in Yemen because households were more dispersed and in less-secure areas, food shipments had to be brought directly to villages. In the case of Yemen, cash beneficiaries traveled further (to post offices) to collect their transfers.

\footnotetext{
${ }^{5}$ These calculations abstract from a number of fixed costs associated with setting up these payments. For example, there were additional costs associated with writing the computer programs needed to dispense payments through the mobile ATMs. Costs such as these are not included in the calculations reported here. We exclude costs that were common to both the food and cash payments such as costs associated with implementing the public works, identifying the beneficiaries, program sensitization, identification of implementing partners, and contract negotiations with the microfinance institutions (MFIs) selected to implement this intervention.
} 
Table 4.1 Modality-specific transfer costs in Ecuador, Uganda, Yemen, and Niger

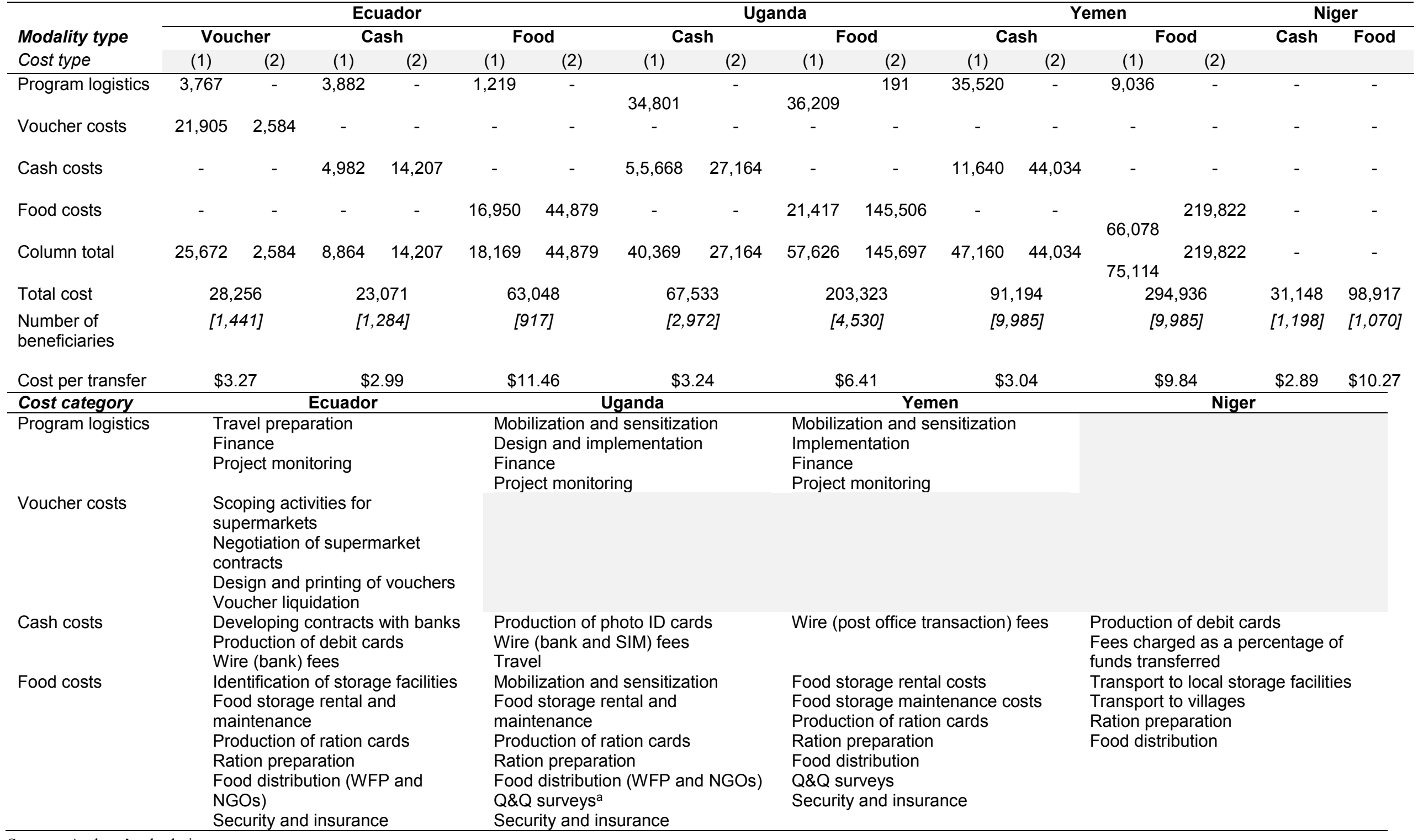

Source: Authors' calculations.

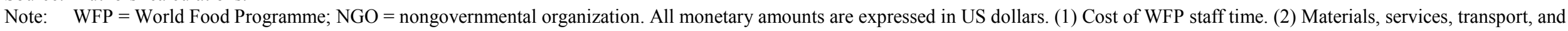
other non-WFP staff costs. ${ }^{a}$ Quantity and quality surveys are quality checks to ensure food rations are not spoilt. 
The breakdown of cash-related costs reveals that the major cost driver for this modality is the execution of payments, which is the transaction fee the partnering organization charges for the release of cash payments. Such fees were approximately 3 percent in Ecuador, Uganda, and Yemen. In Niger, the bank fee was considerably higher, 6 percent.

Since cash transfers were introduced only for these studies, calculation of average costs per beneficiary for cash entails a more straightforward measure of total costs divided by the number of beneficiaries reached. But note that some setup costs of the food distribution system are very likely not captured in the measures of total costs for food (since those setup costs were incurred many years ago), while setup costs of the cash distribution are captured in the measures of total costs for cash (since those setup costs were incurred during the study). In particular, because the cash modality was a new endeavor, start-up activities for it (such as re-verification, security, and other measures) required labor and human resources, while analogous activities for the food modality had been incurred long before the study period and did not appear in project financial records.

A caveat to these results is that differences in the location and operations of distribution points can affect the calculation of modality-specific transfer costs. Hypothetically, if a district has only one cash distribution point but multiple food distribution points, the cost of delivering food will be ceteris paribus higher than the cost of providing cash. Cash would appear less expensive to deliver, but only because the cost of accessing transfers had been shifted from the program to the beneficiary. The household surveys that took place alongside the interventions included a set of questions on the cost of traveling to payment sites, the cost of transport home, the time spent traveling to payment sites, and the time spent at the distribution point waiting for payment. Those are shown in Table 4.2. There is no meaningful difference in private cost - time or money - between obtaining food or cash transfers in Niger or Uganda, a result consistent with both modalities being transported into the villages where beneficiaries reside. Private costs of obtaining food transfers were higher than those associated with cash transfers in Ecuador because the distribution of food took longer and because some households had to purchase transport to take their food rations home. In Yemen, beneficiaries had to travel to local post offices to obtain their cash transfers whereas food was trucked into their villages, so distribution costs were partially shifted to beneficiaries. 
Table 4.2 Private costs of obtaining transfers

\begin{tabular}{|c|c|c|c|c|c|c|c|c|c|}
\hline \multirow[b]{2}{*}{ Modality type } & \multicolumn{3}{|c|}{ Ecuador } & \multicolumn{2}{|c|}{ Uganda } & \multicolumn{2}{|c|}{ Yemen } & \multicolumn{2}{|c|}{ Niger } \\
\hline & Voucher & Cash & Food & Cash & Food & Cash & Food & Cash & Food \\
\hline \multicolumn{10}{|l|}{$\begin{array}{l}\text { Time costs } \\
\end{array}$} \\
\hline $\begin{array}{l}\text { Two-way travel to payment point } \\
\text { (minutes) }\end{array}$ & 56 & 56 & 78 & 76 & 70 & 122 & 74 & - & - \\
\hline $\begin{array}{l}\text { Waiting time at payment point } \\
\text { (minutes) }\end{array}$ & 53 & 16 & 54 & 80 & 86 & 34 & 44 & - & - \\
\hline $\begin{array}{l}\text { Total time spent obtaining } \\
\text { transfer (minutes) }\end{array}$ & 109 & 72 & 132 & 156 & 156 & 156 & 118 & 60 & 60 \\
\hline $\begin{array}{l}\text { Total time spent obtaining } \\
\text { transfer (hours) }\end{array}$ & 1.8 & 1.2 & 2.2 & 2.6 & 2.6 & 2.7 & 1.9 & 1.0 & 1.0 \\
\hline \multicolumn{10}{|l|}{ Monetary costs } \\
\hline $\begin{array}{l}\text { Transport costs as a percentage } \\
\text { of transfer value }\end{array}$ & $4.1 \%$ & $3.7 \%$ & $5.3 \%$ & $0.0 \%$ & $0.0 \%$ & $8.6 \%$ & $2.0 \%$ & $0.0 \%$ & $0.8 \%$ \\
\hline
\end{tabular}

Source: Authors' calculations.

Notes: Total time spent obtaining transfer $=($ two-way travel time $)+$ waiting time. 


\section{ACCOUNTING FOR FOOD PROCUREMENT COSTS}

Our comparative analysis has assumed that the costs of the transfers themselves do not differ across modality. The cost to WFP of the food in each ration is assumed to be equal to the value of each cash transfer. Since the value of the cash transfer was set to the amount required to purchase the food ration in the market, this assumption implicitly translates to assuming that the full cost to WFP for the food in each food ration is the market value of the food. So for example, in the Ecuador case study we assume that it costs WFP \$40 to procure the food basket worth \$40. However, suppose that WFP could procure the items in the Ecuador food basket at a cost below their $\$ 40$ transfer value. If that were the case, it would narrow - and possibly reverse - the cost advantage of the cash modality. To assess this possibility, we worked with WFP staff to calculate the actual procurement costs for the food transfer modality, including the cost of commodities in food rations, external shipping costs, and staff time dedicated to pipeline and procurement activities for two countries where these data were available, Ecuador and Yemen. Table 5.1 shows the results.

In Ecuador, most of the canned fish, rice, lentils, and oil that made up the food basket were procured locally. However, some vegetable oil and lentils were also obtained through international procurement. To assess any difference in cost of procurement by WFP, we collected supplementary data to assess those costs of commodities destined for food baskets in program distribution. External shipping and human resource-related pipeline costs were included for those international commodities procured, while in-country transport was included for locally procured commodities. Based on those data, we estimate that providing a basket of commodities worth $\$ 40$ cost $\$ 46.76$ in food procurement costs. Because the cash transfer was $\$ 40$, this means that accounting for WFP's costs of procuring food increases the difference in providing transfers as food rather than as cash. When we include the food procurement cost and the monetary value of cash and vouchers, we find cash ( $\$ 42.99$ per transfer) and vouchers (\$43.27 per transfer) are even less expensive than food ( $\$ 58.25$ per transfer).

In Yemen, wheat was procured locally while vegetable oil was obtained through international procurement. External shipping costs, stevedoring costs, and customs fees were included for the international commodities, calculated as a percentage amount of the total oil procured for this intervention. The cost of procuring food was less than its market value; it cost WFP $\$ 39.01$ to provide a food basket valued at $\$ 49$. So even though the modality-specific cost of food in Yemen (\$9.84) was higher than for cash (\$3.04), when we include the cost of procurement of the transfer, the cost of food per transfer (\$48.85) was less expensive than that of cash $(\$ 52.04)$. This occurs because at the time of these purchases, WFP was a relatively large buyer in a relatively small market. Another key feature driving this result is that wheat, which made up the largest share of the food ration, was sourced locally. Lentz, Passarelli, and Barrett (2013) note that on average, cereals sourced locally are, relative to international procurement, 53 percent less expensive. Lastly, had the program been expanded, this cost differential would have again narrowed as WFP would have been able to reap scale economies in the delivery of cash that are not available for food. 
Table 5.1 Accounting for procurement costs in Ecuador and Yemen

\begin{tabular}{|c|c|c|c|c|c|c|c|c|c|c|}
\hline \multirow[b]{3}{*}{ Modality type } & \multicolumn{6}{|c|}{ Ecuador } & \multicolumn{4}{|c|}{ Yemen } \\
\hline & \multicolumn{2}{|c|}{ Cash } & \multicolumn{2}{|c|}{ Voucher } & \multicolumn{2}{|c|}{ Food } & \multicolumn{2}{|c|}{ Cash } & \multicolumn{2}{|c|}{ Food } \\
\hline & (1) & (2) & (1) & (2) & (1) & (2) & (1) & (2) & (1) & (2) \\
\hline Program logistics & 3,882 & - & 3,767 & - & 1,219 & - & 35,520 & - & 9,036 & 1,067 \\
\hline Voucher costs & - & - & 21,905 & 2,584 & - & - & - & - & - & - \\
\hline Food costs & - & - & - & - & 16,950 & 44,879 & - & - & 148,878 & 218,755 \\
\hline Cash costs & 4,982 & 14,207 & - & - & - & - & 11,640 & 44,034 & - & - \\
\hline $\begin{array}{l}\text { Cost of transfer (food, } \\
\text { cash, or voucher) }\end{array}$ & - & 308,160 & - & 345,840 & - & 256,572 & - & $1,467,795$ & - & $1,085,809$ \\
\hline Column total & 8,864 & 322,367 & 25,672 & 348,424 & 18,169 & 301,451 & 47,160 & $1,511,829$ & 157,914 & $1,305,631$ \\
\hline Total cost & \multicolumn{2}{|c|}{331,231} & \multicolumn{2}{|c|}{374,096} & \multicolumn{2}{|c|}{319,620} & \multicolumn{2}{|c|}{$1,558,989$} & \multicolumn{2}{|c|}{$1,463,545$} \\
\hline Number of beneficiaries & \multicolumn{2}{|c|}{$[1,284]$} & \multicolumn{2}{|c|}{$[1,441]$} & \multicolumn{2}{|c|}{ [917] } & \multicolumn{2}{|c|}{$[9,985]$} & \multicolumn{2}{|c|}{$[9,985]$} \\
\hline Total cost per transfer & \multicolumn{2}{|c|}{$\$ 42.99$} & \multicolumn{2}{|c|}{$\$ 43.27$} & \multicolumn{2}{|c|}{$\$ 58.25$} & \multicolumn{2}{|c|}{$\$ 52.04$} & \multicolumn{2}{|c|}{$\$ 48.85$} \\
\hline
\end{tabular}

Source: Authors' calculations.

Notes: All monetary amounts are expressed in US dollars. The cost of the food transfer is assessed according to the actual cost of procurement as incurred by WFP. (1) Cost of World Food Programme (WFP) staff time. (2) Materials, services, transport, and other non-WFP staff costs. 


\section{THE IMPACT OF MODALITY-SPECIFIC COST DIFFERENCES ON COVERAGE}

In the four countries we consider here, we have shown that the modality-specific costs of transferring cash are less than those for food. But we have not shown that the differences "matter" in any welfare sense. In this section, we address this concern.

Specifically, suppose that we could redo these interventions, keeping all design and implementation features - payment levels, frequency of payment, location of payment, and so on - the same. We also keep the same aggregate budget for these interventions: \$2 million per country for transfers. Given the information we have on modality-specific costs, we estimate separately the number of beneficiaries we could reach if all transfers were made in cash and the number of beneficiaries we could reach if all transfers were made in food. We can then assess the opportunity cost, in terms of foregone program coverage, of using a higher-cost transfer modality.

Table 6.1 shows the calculations. For each country we report the value of the transfer, the modality-specific cost of using that modality, and, adding those together, and the total cost of making one transfer to a beneficiary. Multiplying this by the number of transfers gives the total cost of providing that transfer to a single household. Next, we take the budget for transfers ( $\$ 2$ million) and divide it by the total cost of a transfer to one household. This gives us the total number of households that could be reached if the entire budget was used for food or for cash. The modality-specific cost of providing food transfers was always higher than for cash. Consequently, as Table 6.1 shows, program coverage could have been increased by 12.7 percent in Niger, 13.06 percent in Yemen, 19.7 percent in Ecuador, and 23.5 percent in Uganda. Across all four countries, an additional 44,769 people could have received assistance at no additional cost had cash been provided instead of food. These calculations change slightly if we take into account food procurement costs. Because in Ecuador food procurement costs were higher than the value of the cash transfer, accounting for that increases the number of people who could have been covered had WFP provided cash to all beneficiaries; the reverse is true in Yemen. 
Table 6.1 Impact of modality-specific cost differences on coverage

\begin{tabular}{|c|c|c|c|c|c|c|c|c|c|}
\hline \multirow[b]{2}{*}{ Modality } & \multirow[b]{2}{*}{ Calculation } & \multicolumn{2}{|c|}{ Ecuador } & \multicolumn{2}{|c|}{ Uganda } & \multicolumn{2}{|c|}{ Yemen } & \multicolumn{2}{|c|}{ Niger } \\
\hline & & Cash & Food & Cash & Food & Cash & Food & Cash & Food \\
\hline Transfer value (US dollars) & $(1)$ & $\$ 40.00$ & $\$ 40.00$ & $\$ 10.25$ & $\$ 10.25$ & $\$ 49.00$ & $\$ 49.00$ & $\$ 55.00$ & $\$ 55.00$ \\
\hline $\begin{array}{l}\text { Modality-specific transfer } \\
\text { cost (US dollars) }\end{array}$ & $(2)$ & $\$ 2.99$ & $\$ 11.46$ & $\$ 3.24$ & $\$ 6.41$ & $\$ 3.04$ & $\$ 9.84$ & $\$ 2.89$ & $\$ 10.27$ \\
\hline Cost of one transfer & $(3)=(1)+(2)$ & $\$ 42.99$ & $\$ 51.46$ & $\$ 13.49$ & $\$ 16.66$ & $\$ 52.04$ & $\$ 58.84$ & $\$ 57.89$ & $\$ 65.27$ \\
\hline Number of transfers & (4) & 6 & 6 & 7 & 7 & 3 & 3 & 6 & 6 \\
\hline $\begin{array}{l}\text { Total cost per beneficiary } \\
\text { household }(\mathrm{HH})\end{array}$ & $(5)=(4) \times(3)$ & $\$ 257.94$ & $\$ 308.76$ & $\$ 94.43$ & $\$ 116.62$ & $\$ 156.12$ & $\$ 176.52$ & $\$ 347.34$ & $\$ 391.62$ \\
\hline Budget for transfers & (6) & $\$ 2,000,000$ & $\$ 2,000,000$ & $\$ 2,000,000$ & $\$ 2,000,000$ & $\$ 2,000,000$ & $\$ 2,000,000$ & $\$ 2,000,000$ & $\$ 2,000,000$ \\
\hline Number of beneficiary $\mathrm{HHs}$ & $(7)=(6) /(5)$ & 7,753 & 6,477 & 21,179 & 17,149 & 12,810 & 11,330 & 5,758 & 5,107 \\
\hline Average $\mathrm{HH}$ size & (8) & 3.8 & 3.8 & 6.2 & 6.2 & 7.1 & 7.1 & 6.8 & 6.8 \\
\hline Number of beneficiaries & $(9)=(8) \times(7)$ & 29,461 & 24,613 & 131,309 & 106,323 & 90,951 & 80,443 & 39,154 & 34,728 \\
\hline Difference & $\begin{array}{c}(10)=\text { Cash } \\
\text { beneficiaries }- \text { food } \\
\text { beneficiaries }\end{array}$ & & & 24 & & & & & \\
\hline Percentage difference & $\begin{array}{c}(11)=[(10) / \text { food } \\
\text { beneficiaries }] \times 100\end{array}$ & & & 23 & & 13. & & & \\
\hline
\end{tabular}

Source: Authors' calculations.

Note: $\mathrm{HH}=$ household . 


\section{CONCLUSION}

This paper contributes to discussions regarding appropriate transfer modalities. We make two contributions. First, we show that ABC-I, or activity-based costing-ingredients, methods can be used to calculate the modality-specific costs of providing food, cash, and vouchers to beneficiaries. Second, we apply this method to beneficiaries in interventions situated in four very different contexts. As we noted in the introduction, a feature of these comparisons is that the implementer, WFP, ensured that all other aspects of the interventions - the targeting of beneficiaries, the size and duration of transfers, and so onwere designed to be the same for these different transfer modalities in each country. This means that our comparisons of the cost of delivering alternative modalities are not confounded by other differences in program design.

We find that the per transfer cost of providing cash is always less than food. The per transfer cost of cash ranges within a narrow band between $\$ 2.89$ per transfer in Niger and $\$ 3.24$ per transfer in Uganda. The cost per food transfer ranges from $\$ 6.41$ (Uganda) to $\$ 11.46$ (Ecuador). On a per transfer basis, cash costs $\$ 3.17$ less to deliver to a beneficiary in Uganda, $\$ 6.80$ less in Yemen, $\$ 7.38$ less in Niger, and $\$ 8.47$ less in Ecuador.

There are caveats to our findings. First, in some circumstances the implementer can exploit its buying power to procure food at below-market prices, which can narrow the cost differential between cash and food. This occurs in Yemen but not Ecuador. Second, our results are derived from the specific circumstances of our four case studies. They do not, for example, examine the comparative cost of transfer modalities in emergency humanitarian settings, where logistical challenges and market function may greatly differ and alter cost structures. Third, these interventions were of relatively short duration and at relatively modest scale. The results are based on programs of a certain duration, 6 to 12 months, so our findings should not be generalized without consideration of how costs may change with increased program duration. Mindful of this, given the budget available for the interventions, an additional 44,769 people could have received assistance at no additional cost had cash been provided instead of food. This suggests that use of higher-cost modalities carries with it a significant opportunity cost, in terms of reduced coverage. 


\section{REFERENCES}

Caldés, N., D. Coady, and J. Maluccio. 2006. "The Cost of Poverty Alleviation Transfer Programs: A Comparative Analysis of Three Programs in Latin America." World Development 34 (5): 818-837.

Coady, D., M. Grosh, and J. Hoddinott. 2004. Targeting of Transfers in Developing Countries: Review of Experience and Lessons. Washington, DC: World Bank.

Devereux, S. 2006. "Cash Transfers and Social Protection." Paper presented at the regional workshop on "Cash Transfer Activities in Southern Africa," Johannesburg, South Africa, October 9-10. http://sarpn.org/documents/d0002199/Cash_Transfer_Devereux_Oct2006.pdf.

Fiedler, J. L., C. A. Villalobos, and A. C. de Mattos. 2008. "An Activity-Based Cost Analysis of the Honduras Community-Based, Integrated Child Care (AIN-C) Programme.” Health Policy and Planning 23 (6): 408427.

Grosh, M., C. del Ninno, E. Tesliuc, and A. Ouerghi. 2008. For Protection and Promotion: The Design and Implementation of Effective Safety Nets. Washington, DC: World Bank.

Harou, A., J. Upton, E. Lentz, C. Barrett, and M. Gomez. 2013. "Tradeoffs or Synergies? Assessing Local and Regional Food Aid Procurement through Case Studies in Burkina Faso and Guatemala." World Development 49: 44-57.

Hidrobo, M., J. Hoddinott, A. Peterman, A. Margolies, and V. Moreira. 2014. "Cash, Food, or Vouchers? Evidence from a Randomized Experiment in Northern Ecuador." Journal of Development Economics 107: 144-156.

Kaplan, R. S., and S. R. Anderson. 2004. "Time-Driven Activity-Based Costing.” Harvard Business Review 82 (11): $131-140$.

Lentz, E., S. Passarelli, and C. Barrett. 2013. "The Timeliness and Cost-Effectiveness of the Local and Regional Procurement of Food Aid." World Development 49: 9-18.

Tan-Torres Edejer, T., R. Baltussen, T. Adam, R. Hutubessy, A. Acharya, D. B. Evans, and C. J. L. Murray. 2003. Making Choices in Health: WHO Guide to Cost-Effectiveness Analysis. Geneva: World Health Organization.

Turney, P. 1996. Activity Based Costing: An Emerging Foundation for Performance Management. Portland, OR, US: Cost Technology. 


\section{RECENT IFPRI DISCUSSION PAPERS}

\section{For earlier discussion papers, please go to www.ifpri.org/pubs/pubs.htm\#dp. All discussion papers can be downloaded free of charge.}

1374. Do girls pay the price of civil war?: Violence and infant mortality in Congo. Olivier Dagnelie, Giacomo De Luca, and Jean-François Maystadt, 2014.

1373. Variable returns to fertilizer use and its relationship to poverty: Experimental and simulation evidence from Malawi. Aurélie Harou, Yanyan Liu, Christopher B. Barrett, and Liangzhi You, 2014.

1372. Drought risk reduction in agriculture: A review of adaptive strategies in East Africa and the Indo-Gangetic Plain of South Asia. Nicola Cenacchi, 2014.

1371. The political economy of MGNREGS spending in Andhra Pradesh. Megan Sheahan, Yanyan Liu, Christopher B. Barrett, and Sudha Narayanan, 2014.

1370. Assessing progress made toward shared agricultural transformation objectives in Mozambique. Todd Benson, Tewodaj Mogues, and Sileshi Woldeyohannes, 2014.

1369. Strategies to control aflatoxin in groundnut value chains. Wojciech J. Florkowski and Shashidhara Kolavalli, 2014.

1368. The agrarian reform experiment in Chile: History, impact, and implications. Alberto Valdés and William Foster, 2014.

1367. What dimensions of women's empowerment in agriculture matter for nutrition-related practices and outcomes in Ghana? Hazel Jean L. Malapit and Agnes R. Quisumbing, 2014.

1366. The Economywide effects of teff, wheat, and maize production increases in Ethiopia: Results of economywide modeling. Todd Benson, Ermias Engida, and James Thurlow, 2014.

1365. Identifying agricultural expenditures within the public financial accounts and coding system in Ghana: Is the ten percent government agriculture expenditure overestimated? Samuel Benin, 2014.

1364. Environmental migration and labor markets in Nepal. Jean-François Maystadt, Valerie Mueller, Ashwini Sebastian, 2014.

1363. The role of agriculture in the fast-growing Rwandan economy: Assessing growth alternatives. Xinshen Diao, Godfrey Bahiigwa, Angga Pradesha, 2014.

1362. Understanding the context for agriculture for nutrition research: Identifying country typologies of child-stunting determinants. Eduardo Maruyama, Laurian J. Unnevehr, and Jiarui Wang, 2014.

1361. Assessing the economic benefits of sustainable land management practices in Bhutan. Ephraim Nkonya, Raghavan Srinivasan, Weston Anderson, and Edward Kato, 2014.

1360. Examining the sense and science behind Ghana's current blanket fertilizer recommendation. Antony Chapoto and Francis Tetteh, 2014.

1359. Aid effectiveness in Ghana: How's the L'Aquila Food Security Initiative Doing? Samuel Benin, Tsitsi Makombe, and Michael Johnson, 2014.

1358. The other Asian enigma: Explaining the rapid reduction of undernutrition in Bangladesh. Derek D. Headey, John Hoddinott, Disha Ali, Roman Tesfaye, and Mekdim Dereje, 2014.

1357. Can market-based approaches to technology development and dissemination benefit women smallholder farmers?: A qualitative assessment of gender dynamics in the ownership, purchase, and use of irrigation pumps in Kenya and Tanzania. Jemimah Njuki, Elizabeth Waithanji, Beatrice Sakwa, Juliet Kariuki, Elizabeth Mukewa, John Ngige, 2014.

1356. The impact of shocks on gender-differentiated asset dynamics in Bangladesh. Muntaha Rakib and Julia Anna Matz, 2014.

1355. Tractor owner-operators in Nigeria: Insights from a small survey in Kaduna and Nasarawa States. Hiroyuki Takeshima, Hyacinth Edeh, Akeem Lawal, and Moshud Isiaka, 2014.

1354. Co-movement of major commodity price returns: A time-series assessment. Francesca de Nicola, Pierangelo De Pace, and Manuel A. Hernandez, 2014.

1353. Bargaining power and biofortification: The role of gender in adoption of orange sweet potato in Uganda. Daniel O. Gilligan, Neha Kumar, Scott McNiven, J. V. Meenakshi, and Agnes Quisumbing, 2014. 


\section{INTERNATIONAL FOOD POLICY}

RESEARCH INSTITUTE

www.ifpri.org

IFPRI HEADQUARTERS

2033 K Street, NW

Washington, DC 20006-1002 USA

Tel.: +1-202-862-5600

Fax: +1-202-467-4439

Email: ifpri@cgiar.org 